\title{
Susceptibility of Hop Crown Buds to Powdery Mildew and its Relation to Perennation of Podosphaera macularis
}

\author{
David H. Gent, ${ }^{\dagger}$ United States Department of Agriculture-Agricultural Research Service, Forage Seed and Cereal Research Unit, and Depart- \\ ment of Botany and Plant Pathology, Oregon State University, Corvallis 97331; and Briana J. Claassen, Megan C. Twomey, Sierra N. \\ Wolfenbarger, and Joanna L. Woods, Department of Botany and Plant Pathology, Oregon State University, Corvallis, 97331
}

\begin{abstract}
In the Pacific Northwestern United States, the hop powdery mildew fungus, Podosphaera macularis, survives overwintering periods in association with living host tissue because the ascigerious stage of the pathogen is not known to occur in this region. Field experiments were conducted over a 5-year period to describe the overwintering process associated with crown bud infection and persistence of $P$. macularis. Surface crown buds increased in abundance and size beginning in early July and continuing until mid-September. Buds of varying sizes remained susceptible to powdery mildew until late September to early October in each of 3 years of experiments, with susceptibility decreasing substantially thereafter. Potted plants were inoculated sequentially during early summer to autumn, then evaluated in the following year for development of shoots colonized by the powdery mildew fungus (termed flag shoots) due to bud perennation. Emergence of flag shoots was asynchronous and associated with shoot emergence and elongation. Flag shoots emerged over a protracted period from late February to early June, year dependent. In all 4 years of experiments, some infected buds broke and produced flag shoots after chemical desiccation of shoots in spring, a common horticultural practice in

hop production conducted to set training timing and eliminate initial inoculum. Flag shoots were most numerous when plants were inoculated with $P$. macularis in early summer and, consequently, when powdery mildew was present throughout the entire period of crown bud development. The number of flag shoots produced was reduced from 6.8- to 46.6fold when comparing the latest versus earliest inoculation dates. However, all inoculation timings yielded flag shoots at some level, suggesting that bud infection that occurs over an extended period of time in the previous season may allow the fungus to perennate. In studies in two commercial hop yards in Washington State, fungicide applications made after harvest reduced the level of powdery mildew on leaves in the current year but did not significantly reduce flag shoots in the following year. Given that bud infection occurred over a 10 -week period, flag shoots developed even when plants were exposed to inoculum in October and some flag shoots survived chemical pruning practices, management efforts seem best directed to both preventative measures to reduce the likelihood of bud infection and remedial practices to physically eliminate infected crown buds in the ensuing year.
\end{abstract}

Disease management efforts are commonly intended to reduce levels of initial inoculum to delay and reduce the extent of epidemic development (Madden et al. 2007; Mundt and Sackett 2012; Mundt et al. 2013). Primary inoculum density is an especially important determinant of epidemic development in diseases caused by biotrophic pathogens whose life cycle is wholly linked to that of the host. In powdery mildew diseases, the severity of the previous season's epidemic can be associated with the severity of the current seasonal epidemic. This is because high inoculum levels tend to increase the quantity of pathogen overwintering (Caffi et al. 2013; Legler et al. 2014) and the extent of epidemic spread (Mundt et al. 2009, 2013; Ojiambo et al. 2017). This provides motivation to understand the mode of and processes associated with perennation.

Perennation of powdery mildew fungi may occur by either the ascigerious stage (chasmothecia) or as mycelium in association with living host tissue, depending on the pathosystem (Jarvis et al. 2002). The latter may be due to the fungus surviving vegetatively on host tissue that does not become fully dormant, long-distance dispersal from inoculum sources in other regions, survival on an alternate host,

${ }^{\dagger}$ Corresponding author: D. H. Gent; E-mail: Dave.Gent@ars.usda.gov

Funding: Financial support was provided by the USDA-ARS CRIS grant 5358-21000-040-00D, Hop Research Council, Washington State Commission on Pesticide Registrations, and Washington State Department of Agriculture Specialty Crops Research Block Grant program (K1508).

Mention of a trademark, proprietary product, or vendor does not constitute a guarantee or warranty of the product by the USDA and does not imply its approval to the exclusion of the products or vendors that may also be suitable.

Accepted for publication 9 January 2018.

This article is in the public domain and not copyrightable. It may be freely reprinted with customary crediting of the source. The American Phytopathological Society, 2018. or via invasion of dormant buds (Glawe 2008). Bud infection may lead to development of the so-called flag shoots, dubbed as such because as infected buds elongate, the associated shoots may be entirely colonized by the fungus and appear as a white flag against a backdrop of otherwise green host tissue. Powdery mildew flag shoots have been described on grape, apple, hop, gooseberry, currant, rose, maple, and dogwood, among other hosts (Jarvis et al. 2002).

Bud perennation is particularly important on hop in the Pacific Northwestern United States. Podosphaera macularis is heterothallic and chasmothecia occur in regions where both mating types of the fungus are present (Wolfenbarger et al. 2015). However, only the MAT1-1 mating type is known to occur in the Pacific Northwest and, thus, the ascigerious stage has not been observed in this region (Gent et al. 2006; Turechek et al. 2001; Wolfenbarger et al. 2015). This situation is particularly unique from a disease management perspective because practices that reduce or eliminate bud perennation could be especially efficacious in delaying disease development.

Little is known about the epidemiology and processes associated with bud perennation of $P$. macularis. Royle (1978) stated that, in England, outbreaks of powdery mildew occurred earlier in the season when mechanical pruning of plants in spring was replaced with chemical desiccation of shoots, which was attributed to development of flag shoots. Pruning, by either mechanical or chemical means, removes aboveground tissue early in the season as a means to synchronize plant growth (Gent et al. 2012; Neve 1991; Probst et al. 2016). In England, Liyanage and Royle (1976) further reported that flag shoot development was associated with exposure of plants to inoculum later in the season (i.e., August) as compared with earlier exposure. Field observations and experiments using potted hop plants kept in varying environments also indicated that flag shoots were more numerous following overwintering at moderate temperatures as compared with lower temperatures (Liyanage and Royle 1976), similar to bud perennation of $P$. leucotricha on apple (Spotts and Chen 1984) and Erysiphe necator on grapevine in Mediterranean climates (Gadoury and Pearson 1988; Legler et al. 2014). 
Flag shoots occur at a low frequency on hop in the Pacific Northwest. During 2000 to 2007, flag shoots were found on approximately $0.69 \%$ of plants of powdery-mildew-susceptible cultivars in Washington and only $0.02 \%$ of plants in Oregon (Gent et al. 2008). Infected shoots can be eliminated or reduced by standard cultural practices such as spring pruning, and the intensity and thoroughness
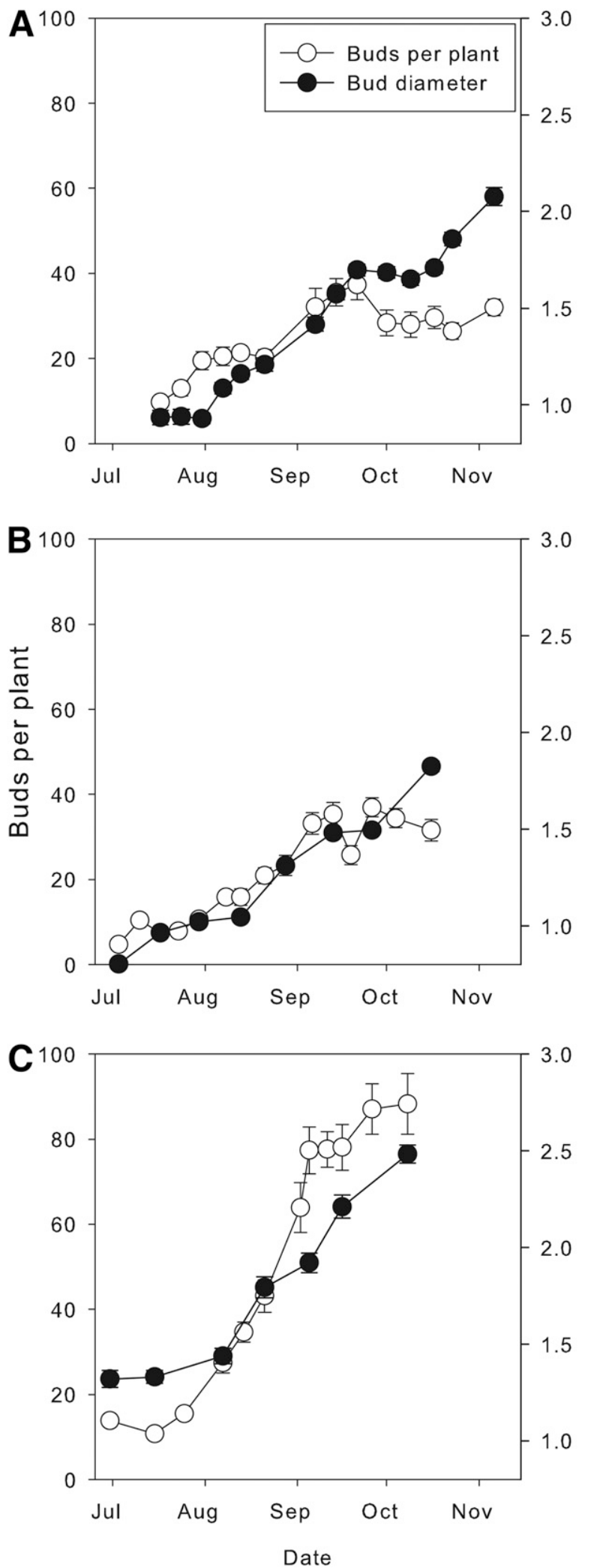

Fig. 1. Phenology of surface crown bud development on young Columbus hop plants. Data are from A, 2012; B, 2013; and C, 2014. of such practices are directly associated with the severity of the disease on both leaves and cones (Gent et al. 2012). Given the extraordinarily poor overwintering survival of the fungus, relatively few flag shoots actually provide the inoculum that incite regional disease epidemics. Furthermore, elimination of flag shoots potentially could have multiyear effects because, in some perennial hosts, flag shoot development is associated with chronic infection of the same plants (Ypema and Gubler 2000).

In this research, we sought to characterize when crown bud infection may occur and the association of infection timing with flag shoot development in the ensuing season. The specific objectives were to (i) describe the temporal development of surface crown buds, (ii) quantify susceptibility of crown buds to powdery mildew throughout their development, and (iii) characterize the dynamics of flag shoot emergence and its relation to timing of bud infection.

\section{Materials and Methods}

Phenology of crown bud development. To develop information on when surface crown buds form on hop, plants of cultivar Columbus were propagated from softwood cuttings in a greenhouse maintained free of powdery mildew by daily atomizing of sulfur. Plants were eventually potted into 4-liter or 20-liter pots. In May 2012, 2013, and 2014, plants were deployed to the Oregon State University Hyslop experimental farm near Corvallis to expose the plants to natural environmental conditions but geographically isolated from other hop yards. The plants were irrigated by drip irrigation up to $4 \mathrm{~h} /$ day and fertilized as needed for normal development. Beginning in early July, the number and diameter of surface crown buds was determined every 1 to 2 weeks on a set of 20 plants. Bud assessments continued until mid-October, when foliage began to senescence.

Susceptibility of crown buds to powdery mildew. Plants of Columbus free of powdery mildew were produced in 4-liter pots and were deployed to the experimental farm in May 2012, 2013, and 2014, as described previously. To determine the relative susceptibility of crown buds of various sizes over time, on each of three dates, 25 pots were retrieved from the field site and taken to a laboratory. These dates were 13 August, 27 September, and 25 October 2012; 12 September, 10 October, and 31 October 2013; and 14 August, 9 September, and 17 October 2014. On each of five plants, buds in four size classes $(1 \leq 0.9 \mathrm{~mm}, 2=0.9$ to $1.3 \mathrm{~mm}, 3=1.3$ to $1.8 \mathrm{~mm}$, and $4>1.8 \mathrm{~mm}$ ) were identified and buds in other size classes were marked with red fabric paint. Buds of the desired size were inoculated with $P$. macularis by touching each bud with a fine paint brush bearing conidia of $P$. macularis. Across all inoculation time points, there were, on average, 13.6 buds of the desired size per plant (standard

Table 1. Tests of fixed effects of crown bud size and date of inoculation with Podosphaera macularis on severity of powdery mildew development on crown buds on potted hop plants of Columbus

\begin{tabular}{lccrc}
\hline Effect $^{\mathbf{x}}$ & Num DF $^{\mathbf{y}}$ & Den DF & $\boldsymbol{F}$ value & $\boldsymbol{P}$ value $^{\mathbf{z}}$ \\
\hline 2012 & & & & \\
$\quad$ Date of inoculation & 2 & 12.21 & 11.71 & 0.001 \\
$\quad$ Bud size & 3 & 34.92 & 0.75 & 0.530 \\
$\quad$ Inoculation $\times$ bud size & 6 & 34.88 & 2.92 & 0.021 \\
2013 & & & & \\
$\quad$ Date of inoculation & 2 & 10.24 & 11.04 & 0.003 \\
$\quad$ Bud size & 3 & 31.77 & 1.18 & 0.331 \\
$\quad$ Inoculation $\times$ bud size & 6 & 31.73 & 3.10 & 0.017 \\
2014 & & & & \\
$\quad$ Date of inoculation & 2 & 130 & 4.19 & 0.017 \\
$\quad$ Bud size & 3 & 130 & 1.13 & 0.334 \\
$\quad$ Inoculation $\times$ bud size & 6 & 130 & 0.71 & 0.643 \\
\hline
\end{tabular}

$\mathrm{x}$ Inoculations were conducted on three dates (August, September, or October) in 2012, 2013, and 2014, targeting buds in four size classes $(<0.9 \mathrm{~mm}, 0.9$ to $1.3 \mathrm{~mm}, 1.3$ to $1.8 \mathrm{~mm}$, and $>1.8 \mathrm{~mm}$ ). On each inoculation date, there were five replicate pots for each bud size class

${ }^{y}$ Numerator and denominator degrees of freedom determined using a general Satterthwaite approximation.

${ }^{\mathrm{z}}$ Analysis was conducted in a general linear mixed model assuming a normal distribution of the response variable. 
deviation 9; range 1 to 57). Inoculum consisted of a mixture of isolates of $P$. macularis obtained from multiple hop yards in Oregon with race Vb,V3,V5 (Wolfenbarger et al. 2016). Five control plants were left uninoculated to quantify potential background infection. After inoculation, plants were placed in a growth chamber maintained at $18^{\circ} \mathrm{C}$ with a 14 -h photoperiod. After 10 to 12 days of incubation, the inoculated buds were removed from the plants and assessed for the percent bud area colonized by the fungus under low magnification $(\times 10$ to $\times 40$ ). The number of buds that died following inoculation also was recorded.

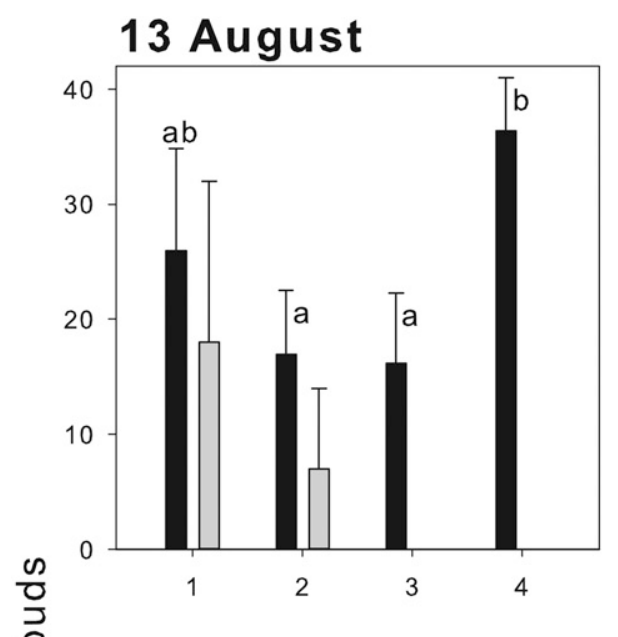

\section{September}

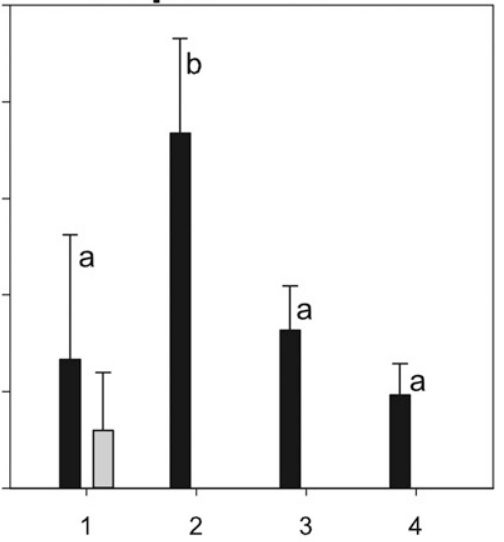

10 October

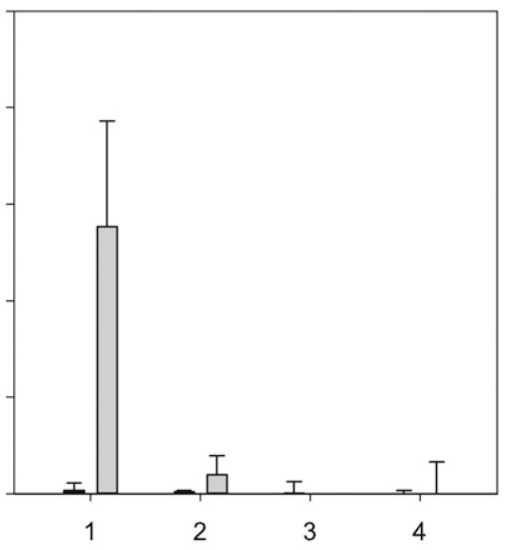

19 September

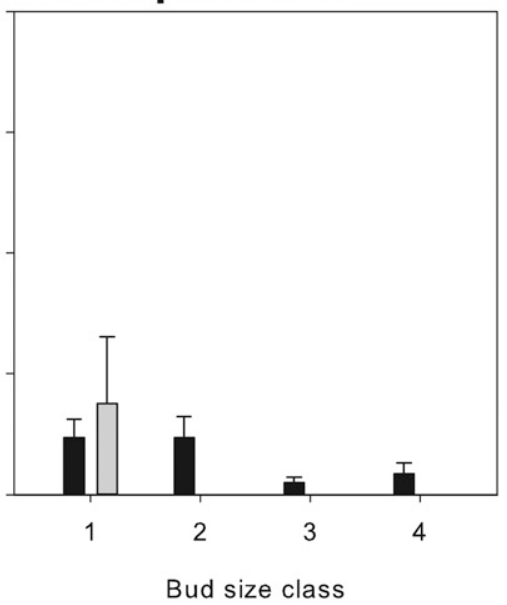

25 October

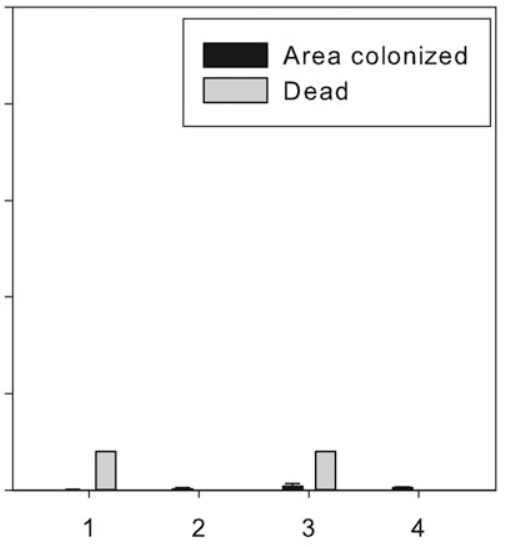

31 October

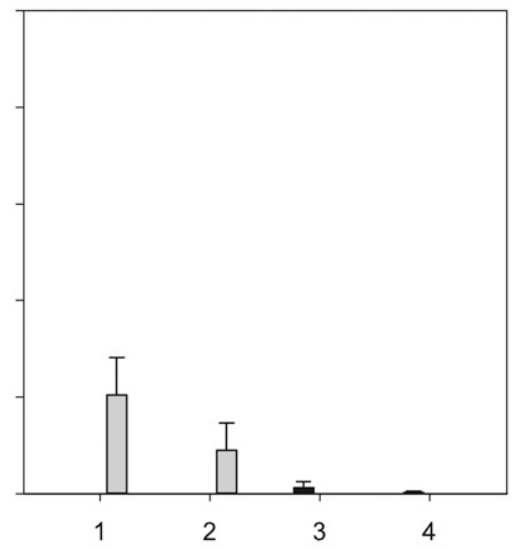

17 October

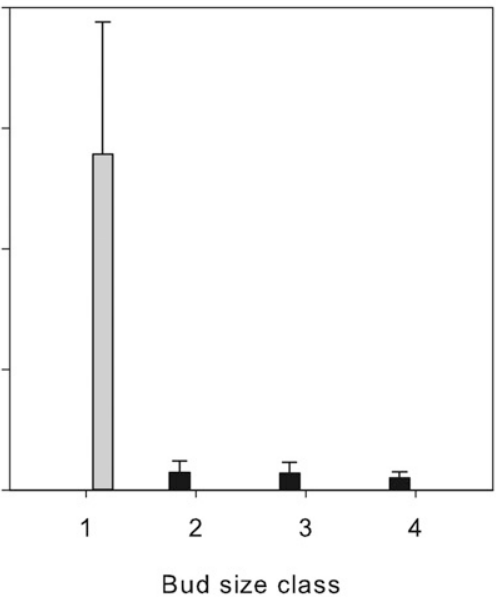

Fig. 2. Severity of powdery mildew (Podosphaera macularis) on hop crown buds and death of buds of varying size when inoculated with powdery mildew during August, September, and October 2012 (top row), 2013 (middle row), and 2014 (bottom row). Data are from cultivar Columbus. In 2012 and 2013, means within a date followed by the same letter or with no letter designation are not significantly different based on a mixed-model analysis $(P=0.05)$. In 2014, date of inoculation was significant in the analysis $(P=0.017)$ whereas the interaction of inoculation date and bud size was not significant $(P=0.643)$. In this year, averaged over bud size class, disease severity was significantly greater following the inoculation on 14 August (5.4\%) than 17 October (1.0\%), and was intermediate on 19 September (2.9\%). Percent dead buds is presented for completeness, although interaction terms for inoculation date-bud size were not significant in any year $(P \geq 0.145)$. 
The experiment was a factorial design with factors of bud size and inoculation date, with experimental units (plants) replicated five times in a completely randomized design. Disease severity data were analyzed in a general linear mixed model in the GLIMMIX procedure in SAS (version 9.4; SAS Institute, Cary, NC). Bud size and inoculation date were fixed factors and plant nested within inoculation date was a random factor. The normal distribution with identity link function was specified. A generalized linear mixed model could not be fit to the data on the proportion of buds killed because of lack of convergence of the maximum-likelihood function, and various transformations of the data yield unsatisfactory residual diagnostics. Therefore, the proportion of buds killed was rank transformed and
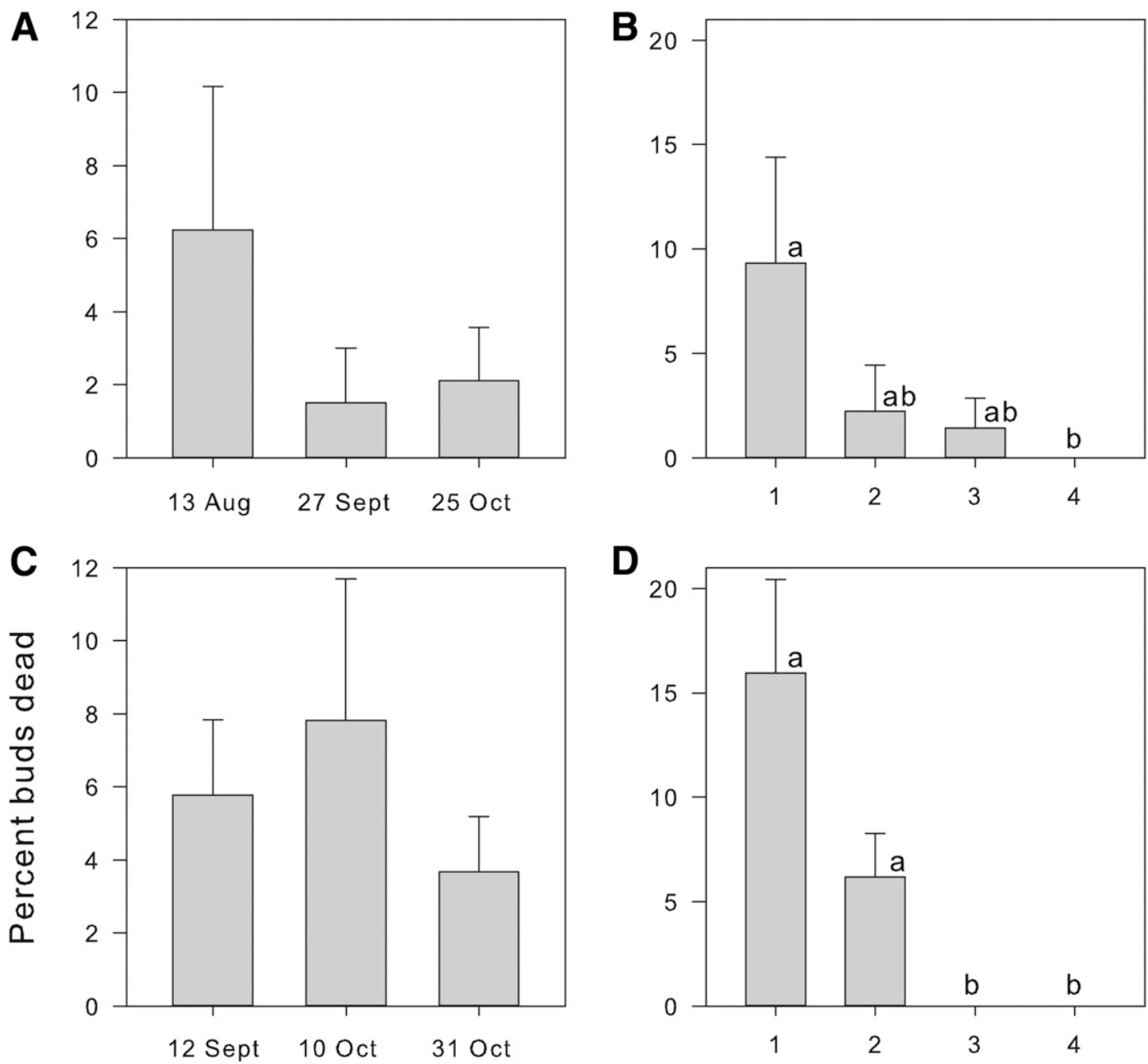

D
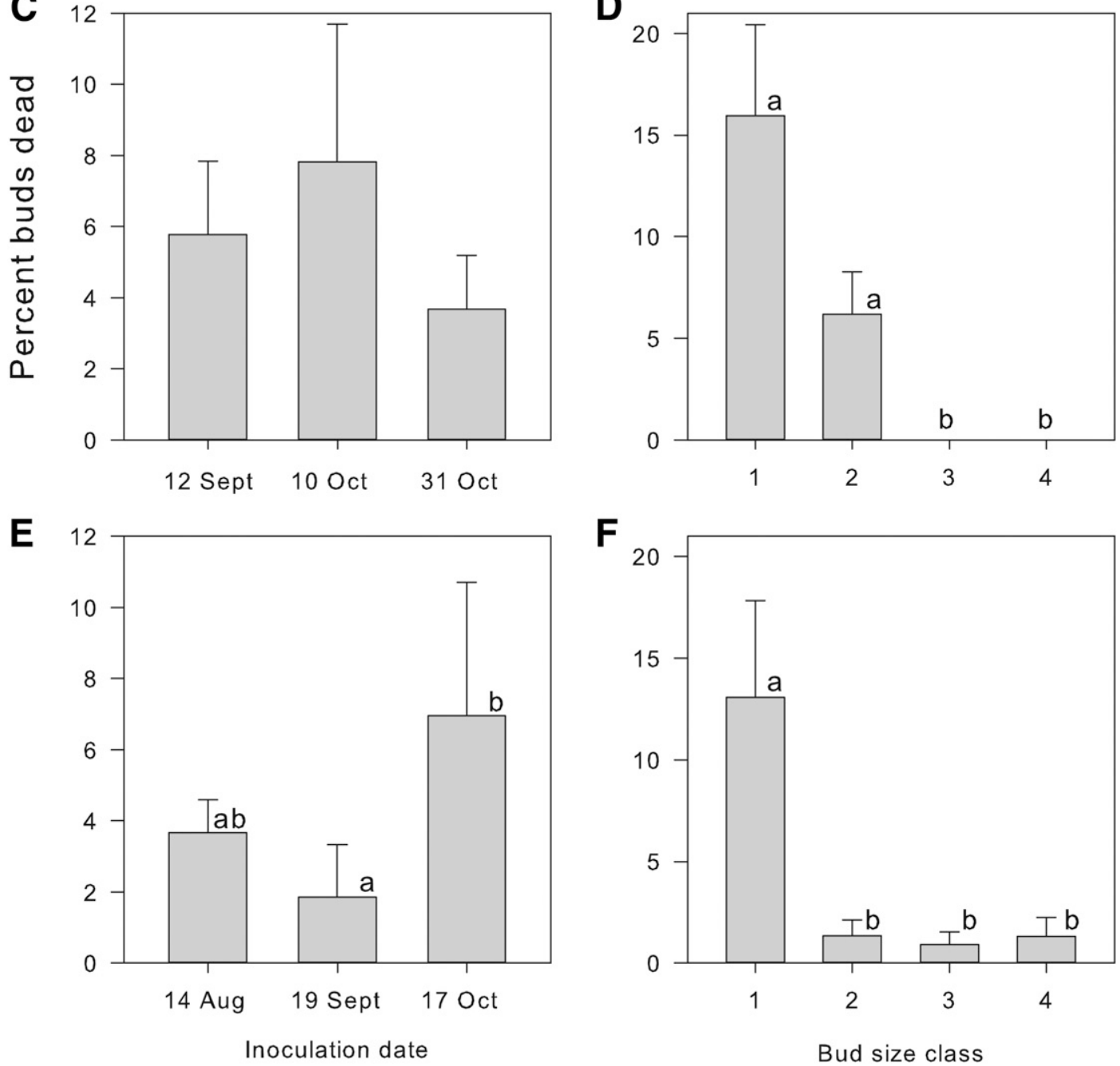

Fig. 3. Death of crown buds on hop plants (Columbus) following inoculation with the powdery mildew fungus, Podosphaera macularis. Buds in various size classes (representing $<0.9 \mathrm{~mm}, 0.9$ to $1.3 \mathrm{~mm}, 1.3$ to $1.8 \mathrm{~mm}$, and $>1.8 \mathrm{~mm}$, respectively) were inoculated on three dates in August, September or October, incubated in controlled conditions, and then rated. Data are from Columbus during A and B, 2012; C and D, 2013; and E and F, 2014. Within a year, means followed by the same letter or with no letter designation are not significantly different based on a nonparametric analysis of rank-transformed means $(P=0.05)$. Interaction terms for inoculation date-bud size were not significant in any year $(P \geq 0.145)$. 
analyzed using a nonparametric method appropriate for a factorial experiment design (Brunner et al. 2002; Shah and Madden 2004). Statistical differences between factors were estimated using contrast statements in the MIXED procedure in SAS.

Flag shoot development. In 2011, 2012, 2015, and 2016, studies were conducted using potted plants to determine when crown bud infection by $P$. macularis is most likely to lead to successful overwintering of the pathogen and flag shoot development the following season. The general procedure was to produce potted plants free of powdery mildew, deploy the plants to an isolated field site to simulate environmental conditions in a natural setting, sequentially inoculate batches of plants, overwinter the plants outdoors, and observe plants in the following season to quantify flag shoot development. A given experiment took approximately 16 months from propagation of plant materials to completion of disease ratings in the following spring, and some changes in experimental approaches were made as suboptimal aspects of the procedure were identified, as detailed below.

Plants of cultivar Symphony were propagated in a greenhouse as noted previously, eventually being up-potted into 20-liter pots. During April or May of each year, plants were deployed to the Hyslop experimental farm or a private farm near Corvallis; both were separated by at least $10 \mathrm{~km}$ from known hop yards. The plants were irrigated by drip irrigation up to $4 \mathrm{~h}$ /day (as needed) and fertilized with approximately $200 \mathrm{ml}$ of a solution of Sunshine Technigro 16-17-17 Plus (SunGro Horticulture, Agawam, MA) biweekly. The plants were treated with paraffinic oil (1\% solution of JMS Stylet Oil; JMS Flower Farms, Vero Beach, FL), potassium bicarbonate (6.8 g/liter as Kaligreen; Otsuka AgriTechno, Tokyo), trifloxystrobin (0.4 g/liter as Flint; Bayer Crop Science, Research Triangle Park, NC), triadimefon $(0.15 \mathrm{~g} / \mathrm{liter}$ as Strike 50 WDG; OHP, Mainland, PA), or cymoxanil (1.2 g/liter as Curzate 60DF; DuPont Crop Protection, Wilmington, DE) every 1 to 4 weeks to minimize the development of powdery mildew and downy mildew (caused by Pseudoperonospora humuli). Applications of trifloxytrobin and triadimefon ceased at least 28 days prior to a given inoculation, as described below; other fungicides were not applied at least 14 days prior to inoculation.

Beginning in early July, batches of approximately 8 to 50 plants were moved from the isolation area to the Oregon State University Lewis-Brown Horticulture Farm south of Corvallis for inoculation. In 2011 and 2012, a suspension of Podosphaera macularis at $1 \times$ $10^{5}$ per $\mathrm{ml}$ of conidia was applied to the cones in various developmental stages, as described in detail by Twomey et al. (2015), and allowed to spread passively to the buds. Following inoculation, the plants were placed in the shade for up to $24 \mathrm{~h}$ to promote infection and then moved to a pot-in-pot system with a replicated block design.

Table 2. Tests of effects of crown bud size and date of inoculation with Podosphaera macularis on death of buds on potted hop plants of Columbus

\begin{tabular}{lcccc}
\hline Effect $^{\mathbf{x}}$ & Num DF & Den DFy & $\boldsymbol{F}$ value & $\boldsymbol{P}$ value $^{\mathbf{z}}$ \\
\hline 2012 & & & & \\
$\quad$ Date of inoculation & 1.88 & 19.1 & 0.59 & 0.545 \\
$\quad$ Bud size & 1.89 & 19.1 & 2.18 & 0.116 \\
$\quad$ Inoculation $\times$ bud size & 3.29 & 19.1 & 0.56 & 0.658 \\
2013 & & & & \\
$\quad$ Date of inoculation & 1.97 & 20.3 & 0.42 & 0.651 \\
$\quad$ Bud size & 1.77 & 20.3 & 13.87 & $<0.001$ \\
$\quad$ Inoculation $\times$ bud size & 3.44 & 20.3 & 1.75 & 0.145 \\
2014 & & & & \\
$\quad$ Date of inoculation & 1.69 & 23.4 & 4.35 & 0.018 \\
$\quad$ Bud size & 2.34 & 23.4 & 6.64 & $<0.001$ \\
$\quad$ Inoculation $\times$ bud size & 3.87 & 23.4 & 1.66 & 0.157 \\
\hline
\end{tabular}

${ }^{x}$ Inoculations were conducted on three dates (August, September, or October) in 2012, 2013, and 2014, targeting buds in four size classes $(<0.9 \mathrm{~mm}, 0.9$ to $1.3 \mathrm{~mm}, 1.3$ to $1.8 \mathrm{~mm}$, and $>1.8 \mathrm{~mm}$ ). On each inoculation date, there were five replicate pots for each bud size class.

y Numerator and denominator degrees of freedom.

${ }^{\mathrm{z}}$ Analysis was conducted using a nonparametric analysis on ranks with an analysis of variance-type statistic (Brunner et al. 2002; Shah and Madden 2004).
Subsequent batches of plants were inoculated every 1 to 4 weeks. In 2011, inoculation dates were 30 June, 7 July, 15 July, 21 July, and 8 August. In 2012, inoculation dates were 6 July, 19 July, 26 July, 9 August, and 14 August. In 2015 and 2016, both cones and leaves were inoculated with a similar titer of inoculum as noted previously. In these years, plants were inoculated approximately monthly beginning in July. In 2015, inoculation dates were 14 July, 11 August, 9 September, and 21 October. Inoculation dates in 2016 were 14 July, 8 August, 29 August, and 4 October. In all years, inoculum of $P$. macularis was collected as described previously and was race $\mathrm{Vb}, \mathrm{V} 3, \mathrm{~V} 5$. As a confirmation of infectivity of the inoculum, greenhouse-produced plants of the same cultivar were inoculated with the spore suspension and maintained at $18^{\circ} \mathrm{C}$ with a 14 -h photoperiod for 10 days.

Following inoculation, the incidence of leaves with powdery mildew was assessed regularly to verify success of the inoculations and subsequent disease development. Ten leaves per plant were inspected for the presence of powdery mildew approximately biweekly beginning 2 weeks after inoculation and continuing until early October.

During October of all years, sawdust was placed in the outer pot up to the soil line of the interior pot in the pot-in-pot system to minimize freezing injury to roots and crown. Beginning in February to early March of the following year, the number of shoots on the plants were counted every 1 to 2 weeks and inspected for the presence of powdery mildew flag shoots. When a flag shoots was found, the diseased shoot was removed to minimize subsequent spread of powdery mildew to other emerging shoots. When the number of newly emerged flag shoots ceased to increase or became indistinguishable from secondary spread of powdery mildew, the foliage was sprayed to runoff with carfentrazone at $0.27 \mathrm{~g} / \mathrm{liter}$ (Aim EC; FMC, Philadelphia) amended with $1 \%$ (volume basis) of MOR-ACT adjuvant (Wilbur-Ellis, Fresno, CA) weekly for 2 to 3 weeks to thoroughly desiccate the foliage. Such chemical desiccation of shoots in spring is a common horticultural practice conducted in hop to both set the timing of training and also reduce inoculum of $P$. macularis and Pseudoperonospora humuli (Gent et al. 2012; Probst et al. 2016). Assessments of the number of healthy shoots and flag shoots continued for an additional 5 weeks as new shoots emerged.

The experiment was structured as a randomized complete block with four replications of each inoculation time point. Data were analyzed in a repeated-measures structure, with fixed factors for date inoculated and rating date and a random factor for block. Multiple covariance structures for the residuals were investigated and the simplest covariance structures consistent with the data were selected based on the Akaike Information Criterion. Degrees of freedom were estimated by the Kenward-Roger approximation method. Data were log transformed to stabilize variances if the maximum-likelihood function in the GLIMMIX procedure did not converge when a Poisson or negative binomial distribution of the response variable was specified.

Persistence of mycelia in and on overwintering buds. To further understand the dynamics of bud infection and persistence of Podosphaera macularis, an experiment was conducted to quantify the presence of mycelia in and on buds during autumn and winter. During the inoculations in July and October 2015 and 2016 described above, 30 to 40 additional pots of Symphony were similarly inoculated and overwintered in the pot-in-pot system. In November of the inoculation year and January of the following year, 15 to 20 pots from each inoculation time (July and October) were selected arbitrarily. Surface crown buds on each pot were removed with a scalpel and enumerated. In 2016, there was an average of 58.0 buds per plant (standard deviation 20.4) and in 2017 there were 47.7 buds/plant (standard deviation 23.7). A subset of 50 buds was dissected and the number of scales per bud was counted to estimate the number of scales per bud. These and the remaining buds were then examined under $\times 40$ magnification to determine the number of buds and bud scales with $P$. macularis. A bud or bud scale was deemed diseased if hyphae or conidiophores typical of the fungus were observed.

The visual identifications were confirmed as $P$. macularis on a subset of 31 putatively infected bud scales by polymerase chain reaction (PCR) with primers specific to the hop powdery mildew fungus. DNA was extracted using a MoBio PowerSoil DNA Isolation Kit 
(MoBio Laboratories, Carlsbad, CA) following the manufacturer's instructions, with polyvinyl pyrrolidone at $0.02 \mathrm{~g} / \mathrm{ml}$ added to buffer S1 to minimize PCR inhibition. Standard PCR assays were conducted using primers (forward primer 5'GGTAGGGCCTCTAGGG TAGG3' and reverse primer 5'AAAGCCTCTCCCATCTTCCTC3') following the conditions described by Liu et al. (2011). Four PCR products were directly sequenced bidirectionally at the Oregon State University Center for Genome Research and Biocomputing. Sequences were compared with a reference isolate of $P$. macularis for confirmation (GenBank accession KX842348.1).

Attempts to fit a generalized linear mixed model to data failed due to lack of convergence of the maximum-likelihood function. Various transformation of the data resulted in unsatisfactory (nonnormal) distribution of residuals. Therefore, the proportion of buds and bud scales with powdery mildew was analyzed using the nonparametric Kruskal-Wallis test (Quinn and Keough 2002) in the NPAR1WAY procedure in SAS. Analyses were conducted by assessment data and year.

Late-season fungicide application experiments. During 2015 and 2016, two experiments were conducted to quantify the impact of late-season fungicide applications directed at basal foliage and crown buds on subsequent development of powdery mildew flag shoots. The experiment in 2015 was conducted in a commercial yard of cultivar Tomahawk located near Toppenish, WA. Treatments consisted of a mineral oil (2\% [vol/vol] HI SUPREME 440 SPRAY OIL-NW; IAP, Fresno, CA) applied two or four times weekly beginning 26 August. These treatments were compared with nontreated plots. Applications were made by a cooperator grower using their standard boom sprayer in an application volume of approximately 468 liters/ha directed at the base of the plants to drench the basal foliage. Treatments were replicated four times each in large plots, where each replicate plot was at 5 rows wide and 1 ha in area.

Disease development on leaves was assessed by inspecting 10 basal leaves on each of 10 plants from the middle row of each plot beginning just before the first treatment was made and every 7 to 14 days thereafter. Relative area under the disease progress curve was then calculated using the trapezoidal method (Madden et al. 2007). On 12 April of the following year, the number of flag shoots present was quantified by inspecting 400 plants in each plot.

The 2016 experiment was structured similarly, with the exception that the study was conducted in a short trellis $(3.1 \mathrm{~m})$ yard of cultivar Cascade near Toppenish, WA. The fungicides evaluated in 2016 consisted of fluopyram + tebuconazole (Luna Experience at $730 \mathrm{ml} / \mathrm{ha}$; Bayer Crop Science) alternated with a mineral oil (1\% [vol/vol] Omni Supreme Spray; Helena Chemical Company, Collierville, TN). As in the 2015 study, applications were made weekly beginning 1 September and consisted of two or four applications total (one or two applications of each fungicide, respectively) and were compared with nontreated

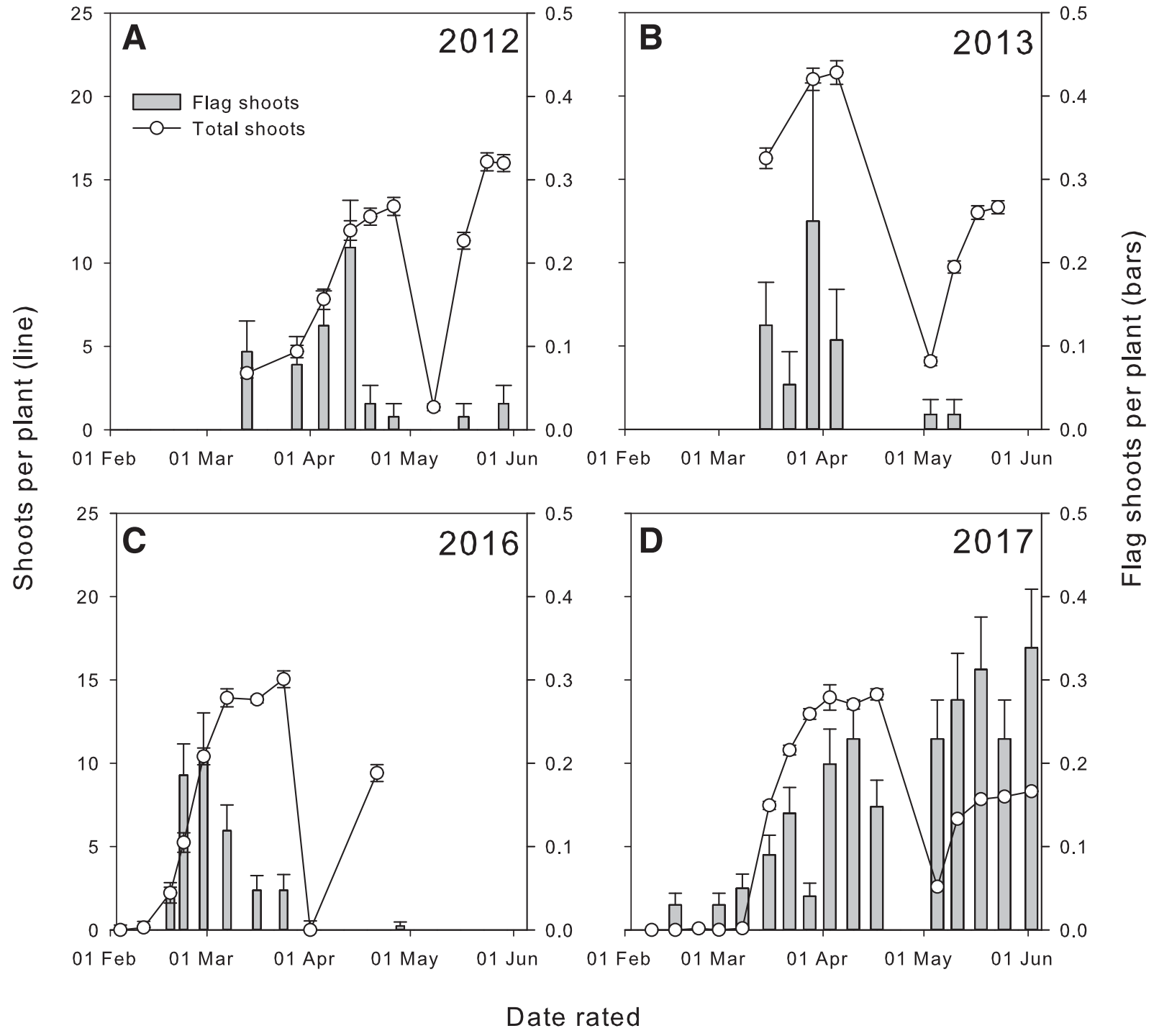

Fig. 4. Emergence of hop shoots (lines) and shoots heavily colonized with powdery mildew, termed "flag shoots" (bars) on Symphony when inoculated with Podosphaera macularis at varying times in the previous year. Data are from A, 2012; B, 2013; C, 2016; and D, 2017. The precipitous decrease in shoots to nearly zero is due to the plant tissue being sprayed with the herbicide carfentrazone to simulate the cultural practice of chemical desiccation (Probst et al. 2016). Error bars denote the standard error of the mean. 
plots. Plot size, experimental design, and disease assessments were as described previously.

Data were analyzed in a generalized linear mixed model using the GLIMMIX procedure in SAS, with fungicide treatments as a fixed effect and block as a random effect. A normal distribution was specified for the relative area under the disease progress curve and a binomial distribution was specified for the incidence of flag shoots. Further, a power analysis was conducted to estimate the likelihood of detecting a significant treatment effect because of the relatively low incidence of flag shoots in commercial hop yards and potential for a type II error. The exemplar data set approach described by Gbur et al. (2012) was used to calculate approximate statistical power. We assumed that the incidence of plants with flag shoots was $0.5 \%$ (i.e., 2 plants in the 400 plants sampled per replicate plot) in the nontreated plots and that a $90 \%$ reduction in flag shoots would be the minimum biologically relevant treatment effect to be detected given the importance of flag shoots as primary inoculum. Four replications of each treatment in a randomized complete block design were utilized with an assumed block level variance of 0.0001 and type I error rate of 0.1 . Power was approximately 0.61 with these conditions.

\section{Results}

Phenology of crown bud development. Small surface crown buds were present by mid-July and both the number and size of the buds increased linearly over time in all years (Fig. 1). On the last assessment date, the number of buds per plant ranged from 33 to 82 and varied in size from 1.8 to $2.5 \mathrm{~mm}$ on average, depending on the year. The number of buds per plant decreased or ceased to increase in late September and early October as some buds broke to form shoots.

Susceptibility of crown buds to powdery mildew. Crown buds in all size classes were susceptible at varying levels to powdery mildew during inoculations in August and September, although their susceptibility decreased significantly when inoculated in October (Table 1; Fig. 2). Temporal trends in bud susceptibility to powdery mildew varied depending on bud size in studies in 2012 and 2013 (inoculation date-bud size interaction, $P \leq 0.021$ ). However, there was not a generalizable trend that was consistent across both years (Fig. 2 ). In 2014 , the severity of powdery mildew on buds depended on

Table 3. Repeated-measures analysis tests of fixed effects for powdery mildew flag shoot emergence on potted Symphony hop plants as influenced by date of inoculation in the previous year and rating date

\begin{tabular}{lccrr}
\hline Effect $^{\mathbf{x}}$ & Num DF & Den DF & $\boldsymbol{F}$ value & $\boldsymbol{P}$ value $^{\mathbf{z}}$ \\
\hline 2012 & & & & \\
$\quad$ Date of inoculation & 4 & 522 & 2.67 & 0.032 \\
$\quad$ Rating date & 9 & 545 & 2.22 & 0.020 \\
$\quad$ Inoculation $\times$ rating date & 36 & 545 & 1.07 & 0.356 \\
2013 & & & & \\
$\quad$ Date of inoculation & 4 & 117 & 0.57 & 0.685 \\
$\quad$ Rating date & 6 & 203 & 12.46 & $<0.001$ \\
$\quad$ Inoculation $\times$ rating date & 24 & 193 & 0.94 & 0.547 \\
2016 & & & & \\
$\quad$ Date of inoculation & 3 & 1,079 & 4.36 & 0.005 \\
$\quad$ Rating date & 10 & 745 & 13.73 & $<0.001$ \\
$\quad$ Inoculation $\times$ rating date & 30 & 745 & 1.76 & 0.008 \\
2017 & & & & \\
$\quad$ Date of inoculation & 3 & 2,681 & 28.66 & $<0.001$ \\
$\quad$ Rating date & 13 & 2,681 & 7.53 & $<0.001$ \\
$\quad$ Inoculation $\times$ rating date & 39 & 2,681 & 0.97 & 0.530 \\
\hline
\end{tabular}

${ }^{x}$ Inoculations were conducted on five dates in 2011 and 2012, and four dates in 2015 and 2016. Ratings for flag shoots occurred the following year as noted in the table.

y Numerator and denominator degrees of freedom determined using a KenwardRodgers approximation.

${ }^{\mathrm{z}}$ Analysis was conducted in a generalized linear mixed model for 2012 data (binomial distribution and logit link function). Other analyses were based on angular- or log-transformed data and a general linear mixed model due to inability to obtain convergence of the maximum-likelihood function for covariance parameter estimates. when buds were inoculated (inoculation date, $P=0.017$ ), independent of bud size (inoculation date-bud size interaction, $P=0.643$ ). In this year, averaged over bud size class, disease severity was significantly greater following the inoculation on 14 August (5.4\%) than 17 October $(1.0 \%)$, and intermediate on 19 September $(2.9 \%)$.

A greater percentage of small buds died following inoculation as compared with larger buds (Fig. 3; Table 2). This was most pronounced for buds $<0.9 \mathrm{~mm}$ in diameter (size class 1) and buds $>1.8 \mathrm{~mm}$ in diameter (size class 4 ). The percentage of small buds inoculated that died ranged from 9.3 to $15.9 \%$ among years, whereas 0 to $1.3 \%$ of the largest buds died (Fig. 3). Inoculation date had a small yet significant effect on bud death in 2014 but not in the other years.

Flag shoot development. Flag shoots emerged in sync with plant growth in late winter and early spring (Fig. 4). Flag shoot emergence occurred over an extended period of time, ranging from as early as 19 February to as late as 29 May. Within a given season, flag shoots emerged over a span of 69 days in 2013 to 99 days in 2017. In 2012 and 2013, flag shoots emerged up to 4 weeks after desiccation of the foliage in early May (Fig. 4A and B).

In repeated measures analyses conducted by year, the number of flag shoots produced clearly depended on the rating date $(P \leq$ 0.020 in all years; Table 3 ), although the effect of timing of inoculation during the previous year varied in a year-dependent manner (Table 3). Inoculation date affected the number of flag shoots produced in 2012, 2016, and $2017(P \leq 0.032)$ but not in $2013(P=$ 0.685 ). In the 3 years when inoculation date was significant, the most flag shoots were produced on plants inoculated with $P$. macularis on the earliest date and the fewest flag shoots were produced on plants inoculated on the latest inoculation date (Fig. 5). The magnitude of the reduction in flag shoots between the earliest and latest inoculations dates varied by year, ranging from 6.8-fold reduction in 2017 to 46.6-fold in 2016. Nonetheless, flag shoots developed at some level in all inoculation timings, including the latest inoculations in October (Fig. 5).

Persistence of mycelia in and on overwintering buds. In all, 29 of the 31 confirmatory PCR yielded a DNA product of the expected size; sequences obtained from the PCR products were identical to each other and the reference isolate of $P$. macularis. In the 2015-16 study, in November, the incidence of buds with external or internal mycelia was similar whether the plants were inoculated in July or October $\left(\chi^{2}=0.08, P=0.779\right.$; Table 4$)$. In contrast, in January, the incidence of infected buds and bud scales was significantly greater in plants inoculated in July (12.8\%) as compared with plants inoculated in October $(0.1 \%)\left(\chi^{2}=12.1, P=0.0005\right)$. The number of infected scales per bud was similarly greater in plants inoculated in July than October (1.02 versus $0.01, \chi^{2}=12.1, P=0.0005$ ).

In the 2016-17 study, the incidence of buds with powdery mildew was $8.2 \%$ greater in the November assessment and $6.1 \%$ greater in the January assessment when the plants were inoculated in July versus October, respectively $\left(\chi^{2}=4.6, P=0.032\right.$ in November; $\chi^{2}=$ $11.1, P=0.0008)$. The number of infected scales per bud in November was statistically similar among the two inoculation dates $\left(\chi^{2}=\right.$ $3.1, P=0.078)$. Clear differences in the number of infected scales per bud were evident during the evaluation 2 months later, in January $\left(\chi^{2}=12.1, P=0.0005\right)$. Thus, in both years of this study $P$. macularis declined more rapidly and survived at lower levels in buds infected in October of the preceding year as compared with July.

Late-season fungicide application experiments. In the 2015 experiment, the relative area under the disease progress curve varied significantly between all treatments, being reduced 0.15 incidencedays in plots treated with fungicides four times and 0.06 incidencedays in plots treated twice $(P<0.001$; Table 5). However, the incidence of plants with flag shoots in spring was similar among treatments $(P=$ $0.919)$. There was only a small effect of fungicides on disease leaves on basal leaves in the 2016 experiment, with incidence-days reduced 0.10 on plants treated with fungicides four times versus twice, and neither treatment was significantly different than nontreated plants $(P=$ 0.067). The incidence of plants with flag shoots in spring was again similar among treatments $(P=0.999)$. 


\section{Discussion}

Successful bud perennation by $P$. macularis requires the coincident occurrence of susceptible crown buds, presence of the pathogen, and environmental conditions permissive for infection and persistence of the fungus. The research described herein points to the intersection of these factors during early summer to early autumn. Crown buds began to develop in early July, just before the time of bloom, with both the number and size of buds increasing linearly until early autumn. Buds of varying size remained susceptible to powdery mildew until early October, when their susceptibility began to decrease substantially. Therefore, susceptible buds with the potential for overwintering are present for approximately 10 weeks during summer and early autumn. This is a time when powdery mildew can readily be found on cones and leaves (Gent et al. 2014), including basal foliage proximal to developing crown buds (Gent et al. 2016). Given this, the likelihood of bud infection and subsequent flag shoot development may be predicated based on when and to what extent powdery mildew occurs during this period. This statement is supported by the inoculation timing studies, which demonstrated that the most flag shoots were found on plants that were inoculated earliest in the preceding year. Thus, buds on the plants inoculated earliest were exposed to powdery mildew for the greatest duration, including the entire periods of their maximum susceptibility.

In this study, the overall tendency was for earlier inoculation to lead to more flag shoots, although even the latest inoculation timing did not preclude flag shoot development. Furthermore, successful bud perennation appears to require infection that penetrates multiple bud scales before bud susceptibility declines in early October with the onset of dormancy. Pearson and Gärtel (1985) found that, on grape, most flag shoots were found on nodes 3 to 5 on first-year canes, and grape buds that result in flag shoots are thought to be infected by E. necator early in the growing season (Pearson and Gärtel 1985; Rumbolz and Gubler 2005; Ypema and Gubler 2000). In apple, flag shoots generally arise from the terminal and two distal auxiliary buds, suggesting that infection that leads to successful perennation occurs later in bud development (Butt 1972). However, fungicide application regimes made late in the season did not directly support later bud infection on apple but indicated that early-season disease management decreased the number of flag shoots (Butt 1972).

In 1 year of investigations in England, bud infection and flag shoot development on hop was maximal when potted plants were placed outdoors in August versus earlier dates in June and July (Liyanage 1973). However, bud infection and perennation of the fungus was observed in all deployment times investigated. This apparent discrepancy between the work of Liyanage (1973) and the present study might be explained by small differences in methods, such as cultivar or direct inoculation used herein compared with passive inoculation in the former study.

It is possible that the size of a bud when it is first infected may influence overwintering survival of that bud. In the studies targeting buds of specific sizes, a greater proportion of small-diameter buds were killed following inoculation as compared with larger buds. Whether the death of those smaller buds was directly from infection by $P$. macularis or natural attrition cannot be known with certainty from the present studies. Nonetheless, bud death due to infection
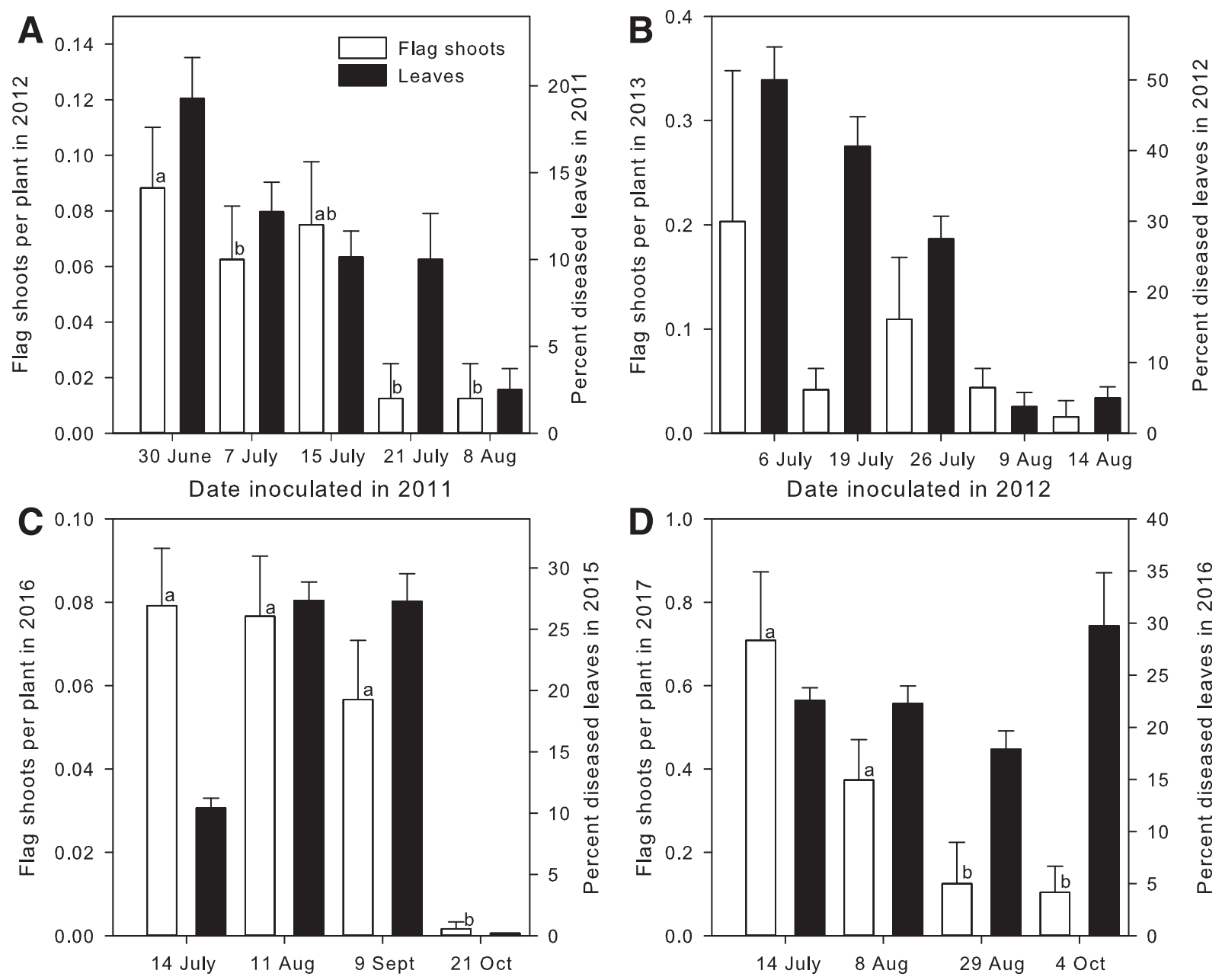

Date inoculated in 2015

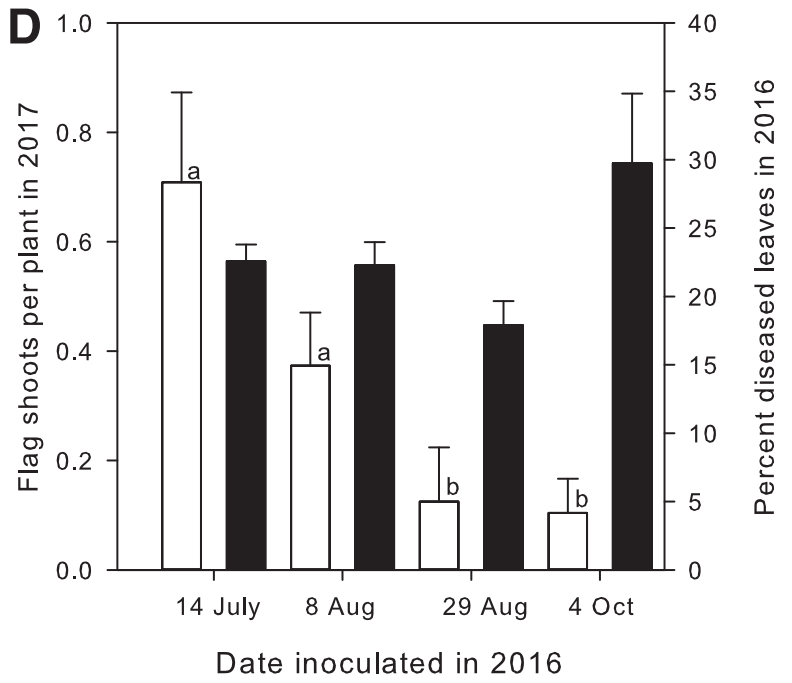

Fig. 5. Powdery mildew flag shoot development on potted hop plants of Symphony in relationship to date of inoculation and severity of disease during the preceding year (represented as percent diseased leaves). Data are from A, 2011; B, 2012; C, 2015; and D, 2016. Means for flag shoots with the same letter are not significantly different based on a repeated measures analysis $(P=0.05)$. Error bars indicate standard errors. 
by powdery mildew fungi is known in other pathosystems (Covey 1969; Prfece 1965; Spotts and Chen 1984) and bud perennation may be moderated by the propensity for later bud death following severe infection (Liyanage and Royle 1976).

There were relatively more buds that were found to be infected with P. macularis in January ( 7.1 to $12.8 \%$ of buds on plants inoculated in July; Table 4) than flag shoots produced from the same plants $(<1$ per plant; Fig. 5). The reason for this difference is unclear. We assume that not all hyphae of the pathogen observed were viable, some infected buds died before assessments of flag shoot were conducted or did not grow during the time of the assessments, or the fungus perished due to unfavorable weather conditions before a flag shoot could be recognized. All of these scenarios are possible but speculative.

In commercial hop production, flag shoots are relatively rare events (Gent et al. 2008; Liyanage and Royle 1976) and even under the fairly extreme disease pressure in the experimental conditions here, the number of flag shoots generated was, on average, less than 1 per plant (Fig. 5). The infrequency of flag shoot development and the findings from this study may indicate that bud perennation requires relatively high levels of inoculum over a relatively long period of time (e.g., during bloom to late September). This condition would tend to be met in situations where powdery mildew developed early in the season and at high levels, which occurs most commonly where flag shoots are preexisting (Gent et al. 2012; Probst et al. 2016; Royle 1978). Thus, occurrence of flag shoots, begetting severe earlyseason powdery mildew, begetting later bud infection, could result in chronic occurrence of flag shoots in a hop yard. A similar phenomenon is known to occur on grape, where it is more common to find flag shoots on a plant or in an area of a field that was near a flag shoot the previous year (Sall and Wrysinski 1982; Ypema and Gubler 2000).

We found no evidence that late-season fungicide applications suppressed flag shoots at biologically relevant levels. However, the lack of statistical significance in this study should be interpreted carefully because there are multiple possible causes, and potential interpretations, of statistical nonsignificance. One interpretation is that there may not be a large effect of late-season fungicide applications on flag shoot development. These applications simply may be inefficient at preventing bud infection, or the timing of the applications may be too late to reduce the early-summer bud infections that are most likely to lead to survival of the fungus. However, another plausible interpretation of the data is that the rarity of flag shoots and consequent low statistical power obscured true treatment effects. As described previously, the approximate power of the generalized linear mixed models was 0.61 . However, power of at least 0.8 often is desired to control type II errors at an acceptable level (Cohen 1988). Additionally, the impact of fungicides on overwintering inoculum may depend on previous disease levels, as well as the timing and severity of disease late in the season. Therefore, the results should be interpreted strictly within the context of the present study.

In spring, flag shoot emergence is highly asynchronous and may occur over a period spanning from the earliest emergence of shoots in late winter to as late as June. Although chemical desiccation of shoots greatly reduced the number of flag shoots, in all years of this study, flag shoots were still observed after desiccation. The thoroughness of spring pruning practices by both chemical and mechanical means is associated with the later severity of powdery mildew on leaves and, to a lesser extent, cones (Gent et al. 2012; Probst et al. 2016; Turechek et al. 2001). Chemical desiccation of shoots is often utilized in place of mechanical pruning methods (Mahaffee et al. 2003) because the former is less expensive, more easily deployed over large areas, and avoids some logistical constraints (Probst et al. 2016). However, the present study indicates that even thorough chemical pruning practices might allow the fungus to persist and initiate later disease outbreaks. In England, Royle (1978) recorded a general observation that powdery mildew outbreaks occurred earlier as pruning methods shifted from mechanical pruning to chemical methods. In the Pacific Northwestern United States, it may be especially important to consider field history and the likelihood of flag shoot development when determining pruning method, given that bud perennation is the only overwintering pathway of the fungus in this environment (Wolfenbarger et al. 2015).

Table 4. Occurrence and persistence of Podosphaera macularis on surface crown buds of hop plants inoculated in early summer or autumn ${ }^{\mathrm{y}}$

\begin{tabular}{|c|c|c|c|c|}
\hline \multirow[b]{2}{*}{ Inoculation date $\mathrm{z}^{\mathrm{z}}$} & \multicolumn{2}{|c|}{ November assessment } & \multicolumn{2}{|c|}{ January assessment } \\
\hline & Buds infected (\%) & Scales infected/bud & Buds infected (\%) & Scales infected/bud \\
\hline \multicolumn{5}{|l|}{2015} \\
\hline July & $8.7 \mathrm{a}$ & - & $12.8 \mathrm{a}$ & $1.02 \mathrm{a}$ \\
\hline October & $5.3 \mathrm{a}$ & - & $0.1 \mathrm{~b}$ & $0.01 \mathrm{~b}$ \\
\hline \multicolumn{5}{|l|}{2016} \\
\hline July & $12.5 \mathrm{a}$ & $0.41 \mathrm{a}$ & $7.1 \mathrm{a}$ & $0.33 \mathrm{a}$ \\
\hline October & $4.3 \mathrm{~b}$ & $0.11 \mathrm{a}$ & $1.0 \mathrm{~b}$ & $0.02 \mathrm{~b}$ \\
\hline
\end{tabular}

y Data were analyzed using the nonparametric Kruskal-Wallis test. Within a year and assessment period, means followed by different letters differ significantly $(P=0.05)$. Note that, in the November assessment in $2016, P=0.078$ for the number of scales infected/bud. The symbol - indicates that a measurement was not made.

${ }^{\mathrm{z}}$ During July and October of each year, 30 to 40 potted plants of Symphony were inoculated with a suspension of P. macularis conidia. In November of the inoculation year and January of the following year, 15 to 20 pots from each inoculation time were selected and all surface crown buds were inspected for signs of P. macularis.

Table 5. Effect of fungicide applications made late in the season on hop leaves with powdery mildew and the incidence of flag shoots in the following spring

\begin{tabular}{lcccc}
\hline & \multicolumn{2}{c}{$\mathbf{2 0 1 5}$} & \multicolumn{2}{c}{$\mathbf{2 0 1 6}$} \\
\cline { 2 - 5 } Treatment $^{\mathbf{y}}$ & RAUDPC $^{\mathbf{z}}$ & Plants with flag shoots (\%) & & RAUDPCz $^{\text {Plants with flag shoots (\%) }}$ \\
\hline Nontreated & $0.18 \mathrm{a}$ & 0.25 & $0.23 \mathrm{ab}$ & 0 \\
Two applications & $0.12 \mathrm{~b}$ & 0.06 & $0.25 \mathrm{a}$ & 0.19 \\
Four applications & $0.03 \mathrm{c}$ & 0.58 & $0.15 \mathrm{~b}$ & 0.06 \\
$P$ value & $<0.001$ & 0.919 & 0.067 & 0.999 \\
\hline
\end{tabular}

y Fungicides were applied to the basal foliage of plants beginning in late August (2015) or early September (2016) in large-scale plots established in commercia hop yards near Toppenish, WA planted to cultivars Tomahawk (2015) and Cascade (2016). In 2015, treatments consisted of a mineral oil applied two or four times weekly beginning 26 August. In 2016, plants were treated weekly with fluopyram + tebuconazole alternated with a mineral oil beginning 1 September.

${ }^{\mathrm{z}}$ Relative area under the disease progress curve (RAUDPC) based on assessment of the incidence of basal leaves with powdery mildew. Disease assessments were conducted beginning on the day of the first fungicide application through early October. Within a year, means followed by the same letter or with no letter designation are not significantly different based on a mixed model analysis $(P=0.05)$. 
Given the apparent absence of the ascigerious stage of $P$. macularis in the Pacific Northwestern United States (Wolfenbarger et al. 2015) and low overwintering survival of the fungus in commercial hop yards, elimination of flag shoots from a subset of hop yards could influence disease levels regionally. Powdery mildew pathogens have short generation times, large reproductive capacities, and a propensity for long-distance dispersal. These life history characteristics make spread of powdery mildews among fields probable at the landscape level, necessitating scaling of disease management efforts (Irwin 1999). An important aspect of such scaling efforts likely will involve elimination of flag shoots as factors that contribute to the probability of bud infection and overwintering are better elucidated.

\section{Acknowledgments}

We thank E. Lizotte for providing insightful comments that improved this article; and N. Adair, L. Ball, and A. Iskra for their valuable technical assistance in this project.

\section{Literature Cited}

Brunner, E., Domhof, S., and Langer, F. 2002. Nonparametric Analysis of Longitudinal Data in Factorial Experiments. John Wiley and Sons, New York.

Butt, D. J. 1972. The timing of sprays for the protection of terminal buds on apple shoots from powdery mildew. Ann. Appl. Biol. 72:239-248.

Caffi, T., Legler, S. E., Bugiani, R., and Rossi, V. 2013. Combining sanitation and disease modelling for control of grapevine powdery mildew. Eur. J. Plant Pathol. 135:817-829.

Cohen, J. 1988. Statistical Power Analysis for the Behavioral Sciences, 2nd ed. Erlbaum, Hillsdale, NJ.

Covey, R. P. 1969. Effect of extreme cold on the overwintering of Podosphaera leucotricha. Plant Dis. Rep. 53:626-630.

Gadoury, D. M., and Pearson, R. C. 1988. Initiation, development, dispersal, and survival of cleistothecia Uncinula necator in New York vineyards. Phytopathology 78:1413-1421.

Gbur, E. E., Stroup, W. W., McCarter, K. S., Durham, S., Young, L. J., Christman, M., West, M., and Kramer, M. 2012. Analysis of Generalized Linear Mixed Models in the Agricultural and Natural Resource Sciences. American Society of Agronomy Soil Science Society of America Crop Science Society of America, Madison, WI.

Gent, D. H., Grove, G. G., Nelson, M. E., Wolfenbarger, S. N., and Woods, J. L. 2014. Crop damage caused by powdery mildew on hop and its relationship to late season management. Plant Pathol. 63:625-639.

Gent, D. H., Mahaffee, W. F., and Turechek, W. W. 2006. Spatial heterogeneity of the incidence of powdery mildew on hop cones. Plant Dis. 90:1433-1440.

Gent, D. H., Nelson, M. E., George, A. E., Grove, G. G., Mahaffee, W. F., Ocamb, C. M., Barbour, J. D., Peetz, A., and Turechek, W. W. 2008. A decade of hop powdery mildew in the Pacific Northwest. Online publication. Plant Health Prog. doi.org/10.1094/PHP-2008-0314-01-RV

Gent, D. H., Nelson, M. E., Grove, G. G., Mahaffee, W. F., Turechek, W. W., and Woods, J. L. 2012. Association of spring pruning practices with severity of powdery mildew and downy mildew on hop. Plant Dis. 96:1343-1351.

Gent, D. H., Probst, C., Nelson, M. E., Grove, G. G., Massie, S. T., and Twomey, M. C. 2016. Interaction of basal foliage removal and late season fungicide applications in management of hop powdery mildew. Plant Dis. 100: 1153-1160.

Glawe, D. A. 2008. The powdery mildews: A review of the world's most familiar (yet poorly known) plant pathogens. Annu. Rev. Phytopathol. 46:27-51.

Irwin, M. E. 1999. Implications of movement in developing and deploying integrated pest management strategies. Agric. For. Meterol. 97:235-248.

Jarvis, W. R., Gubler, W. D., and Grove, G. G. 2002. Epidemiology of powdery mildews in agricultural pathosystems. Pages 169-199 in: The Powdery Mildews, A Comprehensive Treatise. R. Belanger, W. R. Bushnell, A. J. Did, and T. L. W. Carver, eds. American Phytopathological Society, St. Paul, MN.
Legler, S. E., Caffi, T., and Rossi, V. 2014. A model for the development of Erysiphe necator chasmothecia in vineyards. Plant Pathol. 63:911-921.

Liu, Q., Nelson, M. E., and Grove, G. G. 2011. Air sampling of three powdery mildew populations using a Burkard cyclone sampler in eastern Washington. (Abstr.) Phytopathology 101:S106.

Liyanage, A. de S. 1973. Studies on resistance and overwintering in hop powdery mildew (Sphaerotheca humuli (DC) Burr). Ph.D. dissertation, Wye College, University of London, London.

Liyanage, A. de S., and Royle, D. J. 1976. Overwintering of Sphaerotheca humuli, the cause of hop powdery mildew. Ann. Appl. Biol. 83:381-394.

Madden, L. V., Hughes, G., and van den Bosch, F. 2007. The Study of Plant Disease Epidemics. American Phytopathological Society, St. Paul, MN.

Mahaffee, W. F., Thomas, C. S., Turechek, W. W., Ocamb, C. M., Nelson, M. E. Fox, A., and Gubler, W. D. 2003. Responding to an introduced pathogen: Podosphaera macularis (hop powdery mildew) in the Pacific Northwest. Online publication. Plant Health Prog. doi.org/10.1094/PHP-2003-1113-07-RV

Mundt, C. C., and Sackett, K. E. 2012. Spatial scaling relationships for spread of disease caused by a wind-dispersed plant pathogen. Ecosphere 3:1-10.

Mundt, C. C., Sackett, K. E., Wallace, L. D., Cowger, C., and Dudley, J. P. 2009 Aerial dispersal and multiple-scale spread of epidemic disease. EcoHealth 6 : 546-552.

Mundt, C. C., Wallace, L. D., Allen, T. W., Hollier, C. A., Kemerait, R. C., and Sikora, E. J. 2013. Initial epidemic area is strongly associated with the yearly extent of soybean rust spread in North America. Biol. Invasions 15:1431-1438

Neve, R. A. 1991. Hops. Chapman and Hall, London.

Ojiambo, P. S., Gent, D. H., Mehra, L. K., Christie, D., and Magarey, R. 2017 Focus expansion and stability of the spread parameter estimate of the power law model for dispersal gradients. PeerJ. 5:e3465.

Pearson, R. C., and Gärtel, W. 1985. Occurrence of hyphae in buds of grapevine. Plant Dis. 69:149-151.

Prfece, T. F. 1965. Early stages of American gooseberry mildew. Plant Pathol. 14: 83-86.

Probst, C., Nelson, M. E., Grove, G. G., Twomey, M. C., and Gent, D. H. 2016. Hop powdery mildew control through alteration of spring pruning practices. Plant Dis. 100:1599-1605.

Quinn, G. P., and Keough, M. J. 2002. Experimental Design and Data Analysis for Biologists. Cambridge University Press, Cambridge, UK.

Royle, D. J. 1978. Powdery mildew of the hop. Pages 381-409 in: The Powdery Mildews. D. M. Spencer, ed. Academic Press, New York.

Rumbolz, J., and Gubler, W. D. 2005. Susceptibility of grapevine buds to infection by powdery mildew Erysiphe necator. Plant Pathol. 54:535-548.

Sall, M. A., and Wrysinski, J. 1982. Perennation of powdery mildew in buds of grapevine. Plant Dis. 66:678-679.

Shah, D. A., and Madden, L. V. 2004. Nonparametric analysis of ordinal data in designed factorial experiments. Phytopathology 94:33-43.

Spotts, R. A., and Chen, P. M. 1984. Cold hardiness and temperature responses of healthy and mildew-infected terminal buds of apple during dormancy. Phytopathology 74:542-544.

Turechek, W. W., Mahaffee, W. F., and Ocamb, C. M. 2001. Development of management strategies for hop powdery mildew in the Pacific Northwest. Online publication. Plant Health Prog. doi.org/10.1094/PHP-2001-0313-01-RS

Twomey, M. C., Wolfenbarger, S. N., Woods, J. L., and Gent, D. H. 2015. Development of partial ontogenic resistance to powdery mildew in hop cones. PLoS One 10:e120987.

Wolfenbarger, S. N., Massie, S. T., Ocamb, C., Eck, E. B., Grove, G. G., Nelson, M. E., Probst, C., Twomey, M. C., and Gent, D. H. 2016. Distribution and characterization of Podosphaera macularis virulent on hop cultivars possessing R6-based resistance to powdery mildew. Plant Dis. 100:1212-1221.

Wolfenbarger, S. N., Twomey, M. C., Gadoury, D. M., Knaus, B. J., Grunwald, N. J., and Gent, D. H. 2015. Identification and distribution of mating-type idiomorphs in populations of Podosphaera macularis and development of chasmothecia of the fungus. Plant Pathol. 64:1094-1102.

Ypema, H. L., and Gubler, W. D. 2000. The distribution of early season grapevine shoots infected by Uncinula necator from year to year: A case study in two California vineyards. Am. J. Enol. Vitic. 51:1-6. 